\title{
LETTER
}

\section{Optimization of oxygen delivery during high-risk surgery: keeping the concept but refining goals for inotrope infusion?}

\author{
Emmanuel Futier ${ }^{* 1}$ and Benoit Vallet ${ }^{2}$ \\ See related research by Lobo et al., http://ccforum.com/content/15/5/R226
}

We read with great interest the study by Lobo and colleagues [1] in a recent issue of Critical Care. The authors stated that fluid restriction during optimization of oxygen delivery $\left(\mathrm{DO}_{2}\right)$ using dobutamine improves patient outcome after major surgery. Previous studies have shown that hemodynamic optimization using either an individualized goal-directed fluid substitution or an inotrope to maximize $\mathrm{DO}_{2}$ reduces postoperative morbidity and hospital length of stay [2]. Although the study by Lobo and colleagues sheds new light on the use of an inotrope during major surgery, we believe that the approach they support raises some unanswered questions.

Our main concern is about using a specific target value for $\mathrm{DO}_{2}$ - that is, an oxygen delivery index $\left(\mathrm{DO}_{2} \mathrm{i}\right)$ of greater than $600 \mathrm{~mL} /$ minute per $\mathrm{m}^{2}$. It must be emphasized that the treatment goal for $\mathrm{DO}_{2} \mathrm{i}$ was achieved in only a tiny proportion of patients while using high-dose infusions. Also, it may be somewhat confusing for readers to support the benefit of maximizing $\mathrm{DO}_{2}$ while a better outcome was obtained despite slightly lower levels of $\mathrm{DO}_{2} \mathrm{i}$ (though the levels were not significantly lower). One can therefore question the rationale of 'maximization' rather than use an individualized approach of tissue $\mathrm{O}_{2}$ needs.

Adequacy of tissue oxygenation is defined by a $\mathrm{DO}_{2}$ adapted to $\mathrm{O}_{2}$ demand [3]. However, the optimal value of $\mathrm{DO}_{2}$ to meet $\mathrm{O}_{2}$ needs is unknown because of its relationship to metabolic demand and individual variations of the critical $\mathrm{DO}_{2}$ [2]. Therefore, we believe that it is better to address the need for inotrope infusion given the $\mathrm{VO}_{2}$-to- $\mathrm{DO}_{2}$ (oxygen consumption-to-oxygen delivery) relationship (that is, the $\mathrm{O}_{2}$ extraction) or the $\mathrm{VCO}_{2}$-to$\mathrm{DO}_{2}$ (carbon dioxide production-to-oxygen delivery) relationship (or both) [4] rather than to target any specific value for $\mathrm{DO}_{2}$ [3]. Such an approach would help reduce the amount of fluid infused while allowing an individualized inotrope infusion [5].

\section{Authors' response}

Suzana M Lobo, Paulo G Brandão and Francisco R Lobo

We thank Futier and Vallet for addressing some issues in our study. We certainly agree that the goal of $600 \mathrm{~mL} /$ minute per $\mathrm{m}^{2}$ is, to a certain extent, troublesome and that an individualized hemodynamic approach would be more coherent. However, given the findings of two systematic reviews on the use of pre-emptive hemodynamic intervention in high-risk surgical patients $[6,7]$,

*Correspondence: efutier@chu-clermontferrand.fr

'Department of Anaesthesiology and Critical Care Medicine, Estaing Hospital,

University hospital of Clermont-Ferrand, 1 place Lucie Aubrac, 63000,

Clermont-Ferrand Cedex 1, France

Full list of author information is available at the end of the article we accept that $\mathrm{DO}_{2}$, instead of the $\mathrm{VO}_{2}$-to- $\mathrm{DO}_{2}$ relationship, should be the goal of therapy. The review by Hamilton and colleagues [6] included 29 studies involving 4,805 patients. The authors showed significant reductions in mortality by using cardiac index or $\mathrm{DO}_{2}$ as endpoints and not for other goals. Gurgel and do Nascimento [7] reported that therapies directed at increasing central venous oxygen saturation $\left(\mathrm{ScvO}_{2}\right)$ or mixed venous oxygen saturation $\left(\mathrm{SvO}_{2}\right)$ did not significantly reduce mortality. During surgery, many factors influence $\mathrm{VO}_{2}$ and not all are indicative of hypoperfusion [8]. Anesthesia determines a marked decrease in $\mathrm{VO}_{2}$ and carbon dioxide production reflecting reduction in whole-body metabolism.

The critical $\mathrm{DO}_{2}$ is the point below which the dependence between $\mathrm{DO}_{2}$ and $\mathrm{VO}_{2}$ is observed and this point 
varies for different organs [9]. Regional hypoperfusion may occur despite normal global oxygen extraction rate. In our view, it is not the achievement of the ' 600 ' value that determines better outcomes. Rather, what might count is keeping $\mathrm{DO}_{2}$ above baseline while trying to reach this number and, as a consequence, prevent oxygen debt. By targeting a supranormal value, we actually increase the likelihood of having more patients without oxygen debt and for longer periods. In addition, doses of inotropes were not so high and there were no adverse events related to their use. Many changes will come with new knowledge, and still it seems to us that Shoemaker and colleagues [10], who more than 20 years ago reported the close correlation between $\mathrm{DO}_{2}$ and the development of multiple organ failure and death, are right.

Abbreviations

$\mathrm{DO}_{2}$, oxygen delivery; $\mathrm{DO}_{2}, \mathrm{i}$, oxygen delivery index; $\mathrm{VO}_{2}$, oxygen consumption.

\section{Competing interests}

The authors declare that they have no competing interests.

\section{Acknowledgments}

The statements in this letter do not support the use of a specific treatment protocol or a specific medical device for perioperative goal-directed strategies.

\section{Author details}

'Department of Anaesthesiology and Critical Care Medicine, Estaing Hospital, University hospital of Clermont-Ferrand, 1 place Lucie Aubrac, 63000, Clermont-Ferrand Cedex 1, France. ${ }^{2}$ Anaesthesiology and Critical Care Medicine, University Hospital of Lille, Univ Nord de France, Rue du Pr. Emile Laine, 59037, Lille, France.

Published: 6 February 2012
References

1. Lobo SM, Ronchi LS, Oliveira NE, Brandao PG, Froes A, Cunrath GS, Mishiyama KG, Netinho JG, Lobo FR: Restrictive strategy of intra-operative fluid maintenance during optimization of oxygen delivery decreases major complications after high-risk surgery. Crit Care 2011, 15:R226.

2. Lees $N$, Hamilton M, Rhodes A: Clinical review: goal-directed therapy in high risk surgical patients. Crit Care 2009, 13:231.

3. Vallet B, Futier E: Perioperative oxygen therapy and oxygen utilization. Curr Opin Crit Care 2010, 16:359-364.

4. Vallet B: Intravascular volume expansion: which surrogate markers could help the clinician to assess improved tissue perfusion? Anesth Analg 2011, 112:258-259.

5. Donati A, Loggi S, Preiser JC, Orsetti G, Munch C, Gabbanelli V, Pelaia P, Pietropaoli P: Goal-directed intraoperative therapy reduces morbidity and length of hospital stay in high-risk surgical patients. Chest 2007 132:1817-1824.

6. Hamilton MA, Cecconi M, Rhodes A: A systematic review and meta-analysis on the use of preemptive hemodynamic intervention to improve postoperative outcomes in moderate and high-risk surgical patients. Anesth Anal 2011, 112:1392-1402.

7. Gurgel ST, do Nascimento P Jr.: Maintaining tissue perfusion in high-risk surgical patients: a systematic review of randomized clinical trials. Anesth Analg 2011, 12:1384-1391.

8. Shepherd SJ, Pearse RM: Role of central and mixed venous oxygen saturation measurement in perioperative care. Anesthesiology 2009, 111:649-656

9. Van Bommel J, Trouwborst A, Schwarte L, Siegemund M, Ince C, Henny ChP: Intestinal and cerebral oxygenation during severe isovolemic hemodilution and subsequent hyperoxic ventilation in a pig model. Anesthesiology 2002, 97:660-670.

10. Shoemaker WC, Appel PL, Kram HB, Waxman K, Lee T: Prospective trial of supranormal values of survivors as therapeutic goals in high risk surgical patients. Chest 1988, 94:1176-1185.

doi:10.1186/cc11148

Cite this article as: Futier E, Vallet B: Optimization of oxygen delivery during high-risk surgery: keeping the concept but refining goals for inotrope infusion? Critical Care 2012, 16:409. 